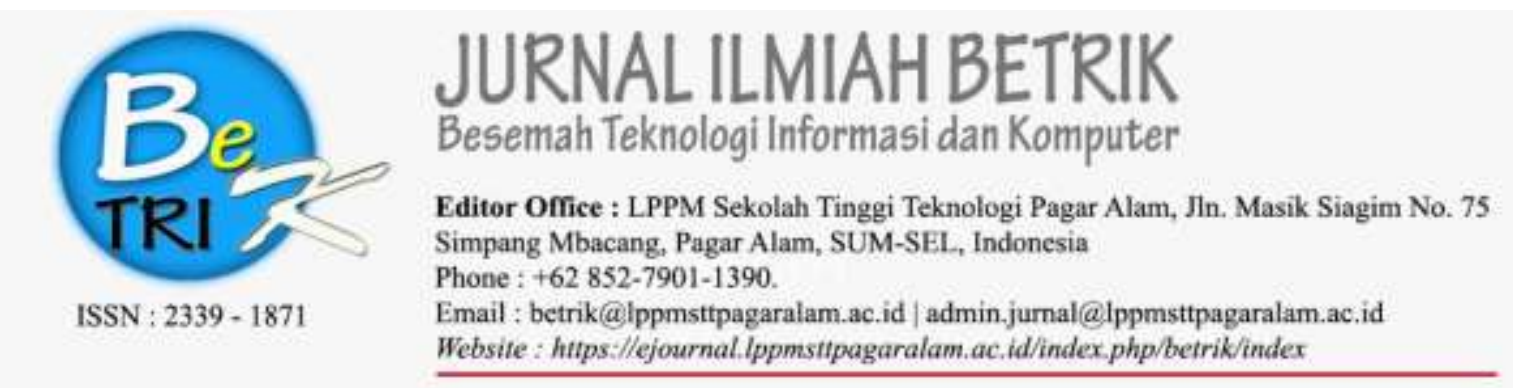

\title{
TATA KELOLA SISTEM MANAJEMEN INFORMASI OBYEK PAJAK MENGGUNAKAN KERANGKA KERJA COBIT 5.0
}

\author{
Popy Prima Sakti \\ Dosen Teknik Informatika Sekolah Tinggi Teknologi Pagar Alam \\ Jalan Masik Siagim No.75 Simpang Mbacang Kec.Dempo Tengah Kota Pagar Alam \\ popyprima_sakti@yahoo.co.id
}

\begin{abstract}
SISMIOP is the heart of the United Nations because all aspects of administrative management that can manage data objects and tax subjects that have been computerized start from the process of data collection, assessment, penyangihan, acceptance and service. The existence of SISMIOP is intended to create an accurate and up to date database by intercepting all UN administration activities into a container, so that the implementation is more uniform, simple, fast and efficient. To know how far the management of the Tax Object Management Information System (SISMIOP) that has been used by the Financial and Asset Management Revenue Service, it is necessary to measure by using good method and framework. The tools or tools used to evaluate the governance of SISMIOP are using Control Objective For Information and Related Technology 5 (COBIT 5.0). The COBIT 5.0 maturity model does not intend to measure a level very accurately or certify when a level is achieved, but rather to a relevant picture or condition of some level of maturity to be achieved, this model is appropriate when management wants to see conformity to the conditions of information technology development And proper maturity.
\end{abstract}

Keywords: SISMIOP, UN, Maturity Level

\begin{abstract}
Abstrak: SISMIOP merupakan jantung PBB karena seluruh aspek pengelolaan administrasinya yang dapat mengelola data objek pajak dan subjek pajak yang sudah terkomputerisasi mulai dari proses pendataan, penilaian, penangihan, penerimaan dan pelayanan. Adanya SISMIOP dimaksudkan untuk menciptakan suatu basis data yang akurat dan up to date dengan menginterasikan semua aktivitas administrasi PBB kedalam suatu wadah, sehingga pelaksanaannya lebih seragam, sederhana, cepat dan efisien. Untuk mengetahui sejauh mana pengelolaan Sistem Informasi Manajemen Obyek Pajak (SISMIOP) yang telah digunakan oleh Dinas Pendapatan Pengelolaan Keuangan dan Aset maka perlu pengukuran dengan menggunakan metode serta kerangka kerja yang baik. Alat atau tools yang digunakan untuk melakukan evaluasi mengenai tata kelola SISMIOP adalah dengan menggunakan Control Objective Fo Information and Related Technology 5 (COBIT 5.0). Maturity model COBIT 5.0 tidak bermaksud untuk mengukur suatu tingkatan secara sangat akurat atau memberikan sertifikasi ketika suatu tingkat tercapai, tetapi lebih kepada suatu gambaran atau kondisi
\end{abstract}


relevan akan beberapa tingkat kematangan yang akan tercapai, model ini sangat tepat ketika manajemen ingin melihat kesesuaian kondisi pengembangan teknologi informasi dan kematangan yang tepat.

Kata Kunci : SISMIOP, PBB, Maturity Level

\section{PENDAHULUAN}

SISMIOP diharapkan dapat mengintegrasikan secara menyeluruh, karena pengelolaan $\mathrm{PBB}$ merupakan suatu sistem pengenaan pajak yang ruwet dan kompleks, dengan banyaknya komponen berbeda serta memiliki fungsi dan tugas yang berbeda pula, masing-masing dengan kepentingan dan sasaran operasionalnya sendiri-sendiri seperti: melayani semua kebutuhan organisasi secara cepat, tepat dan akurat serta handal. Mulai dari data tersebut dimasukkan (key-in) diolah, sampai dihasilkan keluaran (print-out) serta monitoring terhadap hasil keluaran tersebut, baik itu SPPT yang dikeluarkan terhadap pembayaran PBBnya maupun tunggakan yang masih harus ditagih oleh KPPBB. Akan tetapi sasaran keseluruhan pengelolaan Pajak Bumi dan Bangunan adalah meminimalkan biaya operasional untuk meningkatkan penerimaan Pajak Bumi dan Bangunan.

Mengacu pada Keputusan Direktur Jenderal Pajak Nomor KEP-533/PJ/2000 tentang petunjuk pelaksanaan pendaftaran, pendataan dan penilaian Obyek Pajak Bumi dan Bangunan (PBB) dalam rangka pembentukan dan pemeliharaan Basis Data Sistem Manajemen Informasi Obyek Pajak (SISMIOP) sebagai praktik reformasi administrasi perpajakan modern, penelitian ini perlu dilakukan untuk mengetahui apakah
Sistem Informasi Manajemen Obyek Pajak ini sudah berjalan efektif dan sesuai dengan prosedur. Sejauh ini untuk mengetahui sejauh mana pengelolaan Sistem Informasi Manajemen Obyek Pajak (SISMIOP) yang telah digunakan oleh Dinas Pendapatan Pengelolaan Keuangan dan Aset maka perlu pengukuran dengan menggunakan metode serta kerangka kerja yang baik. Alat atau tools yang digunakan untuk melakukan evaluasi mengenai tata kelola SISMIOP adalah dengan menggunakan Control Objective For Information and Related Technology 5 (COBIT 5.0). Maturity model COBIT 5.0 tidak bermaksud untuk mengukur suatu tingkatan secara sangat akurat atau memberikan sertifikasi ketika suatu tingkat tercapai, tetapi lebih kepada suatu gambaran atau kondisi relevan akan beberapa tingkat kematangan yang akan tercapai, model ini sangat tepat ketika manajemen ingin melihat kesesuaian kondisi pengembangan teknologi informasi dan kematangan yang tepat.

Sasongko (2009) menjelaskan COBIT adalah sekumpulan dokumentasi best practices untuk IT Governance yang dapat membantu auditor, pengguna (user), dan manajemen untuk menjembatani gap antara risiko bisnis, kebutuhan kontrol dan masalah-masalah teknis TI. COBIT dikeluarkan ITGI yang dapat diterima secara internasional sebagai praktek pengendalian atas informasi, TI dan risiko terkait. COBIT digunakan untuk menjalankan 
penentuan atas TI dan meningkatkan pengontrolan TI.

Sedangkan menurut ISACA (2012) COBIT 5 adalah salah satu kerangka bisnis untuk tata kelola dan manajemen perusahaan IT. Versi evolusioner ini menggabungkan pemikiran terbaru dalam tata kelelola perusahaan dan teknik manajemen, serta menyediakan prinsipprinsip, praktek, alat alat analisis dan model yang diterima secara umum untuk membantu kepercayaan dan nilai dari sistem informasi.

\section{METODOLOGI}

\subsection{Konsep Model Penelitian}

Kegiatan pengumpulan data yang dilakukan adalah bertujuan untuk mendapatkan data dan informasi yang lebih lengkap. Pengumpulan data dilakukan dengan menggunakan teknik pengumpulan data, baik dengan data primer maupun data sekunder dalam rangka mendeskripsikan variabel-variabel penelitian sebagai berikut :

a. Kuesioner (Questionnaire) penulis memberikan daftar pertanyaan ke pengguna SISMIOP sebagai responden yang digunakan untuk mengevaluasi SISMIOP berdasarkan Maturity Level dari COBIT 5.0.

b. Dokumentasi (Documentations), Pada tahap ini peneliti menggunakan dokumentasi berupa laporan data pembuatan PBB baik penerbitan, mutasi, keberatan maupun penghapusan yang ada di Bidang PBB-P2 DPPKA Kota Pagar Alam.

Dalam penelitian ini masalah yang akan diteliti adalah proses pemanfaatan teknologi informasi yang merupakan program pemerintah daerah khususnya Kota Pagar Alam dalam meningkatkan pendapatan daerah dengan pungutan Pajak Bumi dan Bangunan, penelitian ini memastikan tujuan pemerintah melalui Dinas Pendapatan Pengelolaan Keuangan dan aset Kota Pagar Alam dapat dicapai dengan cara evaluasi (evaluating) terhadap kebutuhan, kondisi dan pilihan bagi pihak pengguna (stakeholder), menetapkan arah (direction), melalui skala prioritas dan pengambilan keputusan, dan pengawasan (monitoring), pada saat pelaksanaan, penyesuaian dan kemajuan terhadap arah dan tujuan yang telah ditetapkan.

\subsection{Rancangan Penelitian}

Penelitian ini juga menghubungkan metode audit, mengumpulkan data (studi lapangan dan studi pustaka) dengan evaluasi tata kelola teknologi informasi terhadap penggunaan kerangka kerja Cobit 5.0. metode analisis dari data yang diperoleh menggunakan SPSS (Statistical Package For Social Sciences) untuk Menentukan nilai maturity level, adapun tahapan dari penelitian ini yaitu:

\section{Studi Kelayakan (Preliminary Study)} merupakan kegiatan awal untuk mempelajari gambaran umum Dinas Pendapatan Pengelolaan Keuangan dan aset Kota Pagar Alam.

2. Menentukan ruang lingkup evaluasi (Establish Materiality and Asses risks) adalah wawancara awal/diskusi bersama pejabat yang terkait dalam pengurusan pajak bumi dan bangunan di Dinas Pendapatan Pengelolaan Keuangan dan Aset Kota Pagar Alam untuk memutuskan ruang lingkup yang 
mencakup proses-proses internal berdasarkan standar COBIT 5.0.

3. Membuat Rencana Evaluasi (Plan the Evaluation) tahap ini dilakukan setelah mengetahui kepastian ruang lingkup yaitu dengan membuat rancangan perkiraan untuk melakukan evaluasi kebagian lain yang terkait dan dapat diselesaikan tepat waktu.

4. Pemetaan evaluasi (Mapping of Evaluation) menentukan point-point penting yang akan digunakan dari pencapaian IT Goals yang diharapkan kerangka kerja COBIT 5.0.

5. Pengumpulan data (Consider Internal Control) mengumpulkan data dengan melakukan studi kelapangan berupa pengamatan (observation), wawancara (interview), kuesioner (questionnaire) dan dokumentasi (documentations).

6. Analisis permasalahan (SPSS Analisys) menganalisis data yang diperoleh dari studi lapangan menggunakan SPSS (statistical package for Social Sciences) untuk menentukan nilai Maturity Level.

7. Mengukur / Menentukan Tingkat Kedewasaan (Capability Maturity Level) perhitungan berdasarkan perhitungan statistik menggunakan analisis SPSS.

8. Memberikan Rekomendasi/Evaluasi (Recomendation/Evaluation Report) memberikan laporan evaluasi dan saransaran kepada Dinas Pendapatan Pengelolaan Keuangan dan Aset Kota Pagar Alam berdasarkan analisis tata kelola IT untuk
SISMIOP menggunakan kerangka kerja COBIT 5.0.

9. Hasil Penelitian Analisis Tata Kelola (Audit Report of Governance IT) Laporan penelitian analisis tata kelola IT untuk SISMIOP menggunakan kerangka kerja COBIT 5.0 di Dinas Pendapatan Pengelolaan Keuangan dan Aset Kota Pagar Alam untuk penelitian.

\section{HASIL}

Langkah Pertama proses analisis tata kelola Sistem Manajemen Informasi Obyek Pajak di Dinas Pendapatan Pengelolaan Keuangan dan Aset Kota Pagar Alam adalah menentukan kebutuhan pihak pengguna (stakeholder needs) yaitu yang dipilih Resource Optimisation. Langkah kedua dari kebutuhan DPPKA Kota Pagar Alam diturunkan menjadi tujuan perusahaan (enterprise goals) dan yang diambil hanya data yang primary dapat dilihat pada tabel di bawah ini :

Tabel 1.Tujuan Perusahaan

\begin{tabular}{|c|c|c|}
\hline $\begin{array}{c}B S C \\
\text { dimension }\end{array}$ & Enterprise Goal & $\begin{array}{c}\text { Relation to } \\
\text { governance } \\
\text { Objective } \\
\text { Resource } \\
\text { Optimisation }\end{array}$ \\
\hline Customer & $\begin{array}{l}\text { 9. Informations-based } \\
\text { strategic decision } \\
\text { making } \\
\text { 10. Optimisation of } \\
\text { service delivery costs }\end{array}$ & $\mathrm{P}$ \\
\hline Internal & $\begin{array}{l}\text { 11. Optimisations of } \\
\text { business process } \\
\text { functionality } \\
\text { 12. Optimisations of } \\
\text { business process } \\
\text { costs } \\
\text { 14. Operational and } \\
\text { staff productivity }\end{array}$ & $\mathrm{P}$ \\
\hline $\begin{array}{l}\text { Learning } \\
\& \text { Grow }\end{array}$ & $\begin{array}{l}\text { 16. Skilled and } \\
\text { motivated people }\end{array}$ & $P$ \\
\hline
\end{tabular}


Langkah ketiga setelah didapat tujuan perusahaan diturunkan menjadi tujuan yang berhubungan dengan teknologi informasi dan dapat dilihat di tabel dibawah ini :

Tabel 2. Tujuan Perusahaan yang berhubungan dengan Teknologi Informasi

\begin{tabular}{cc}
\hline BSC dimension & IT - Related Goals \\
\hline Financial & 1. Alignment of IT and business \\
& strategy \\
04. Managed IT-related \\
business risk \\
05. Realised benefits from IT- \\
enabled investments and \\
services portfolio \\
06. Transparency of IT costs, \\
benefits and risk \\
O7. Delivery of IT service in line \\
with business requirements \\
08. Adequate use of \\
applications, information and \\
technology solutions \\
09. IT agility \\
11. Optimisation of IT assets, \\
recources and capabilities \\
12. Enablement and support of \\
businessprocesses by \\
integrating applications and \\
technology into business \\
processes \\
14. IT compliance with internal \\
policies \\
16. Competent and motivated \\
business and IT personnel \\
\end{tabular}

Langkah keempat yaitu tujuan informasi diturunkan lagi menjadi tujuan pemicu dan didapatla tujuanya di dalam tabel di bawah ini :

Tabel 3. Tujuan Teknologi Informasi diturunkan menjadi tujuan pemicu Cobit 5 Process

\begin{tabular}{cl}
\hline Evaluate, direct \& Monitor & EDM02 Ensure \\
& Benefits Delivery \\
& EDM04 Ensure \\
& Resource Optimisation \\
\hline Align,Plan\&Organize & APO01 Manage the IT \\
& Management \\
& Framework \\
& APO03 Manage \\
& Enterprise Architecture \\
& APO07 Manage \\
& Human Resources \\
\hline
\end{tabular}

\begin{tabular}{cl}
\hline & APO08 Manage \\
& Relationships \\
& APO13 Manage \\
& Security \\
\hline Build,Acquire\&Implement & BAI01 Manage \\
& Programmes and \\
& project \\
& BAI02 Manage \\
& Requirements \\
& Definition \\
& BAI04 Manage \\
& Availability and \\
& Capacity \\
\hline Deliver,Service\&Support & DSSO1 Manage \\
& Operation \\
& DSS03 Manage \\
& Problems \\
& DSS04 Manage \\
& Continuity \\
\hline Monitor,Evaluate\&Assess & MEA01 Monitor, \\
& Evaluate and Assess \\
& Performance \\
\hline
\end{tabular}

Dari hasil Pemetaan Enabler Process (tujuan pemicu) yang sudah didapat maka dibuatlah 3 pertanyaan untuk responden untuk hasil pengukuran yaitu bagian dari tujuan bisnis, terkait dengan penyediaan informasi yang tepat bagi manajemen untuk mendukungan operasional suatu entitas dan menjalankan tanggung jawab tata kelolanya memiliki nilai keandalan (realibility) sebesar $68,00 \%$ dari semua responden. Terkait dengan kepatuhan (complience) pada hukum, regulasi maupun perjanjian kontrakyang berhubungan dengan Sistem Manajemen Informasi Obyek Pajak masih rendah yaitu memiliki nilai sebesar $32,00 \%$ dari semua responden.

Pengukuran Optimalisasi Aset teknologi informasi, sumber daya dan kemampuan (Optimisation of IT Assets, Resources and capability) yaitu pada domain EDM02, EDM04, APO01, APO03, APO04, APO07, APO08, APO013, BAI01, BA102, BAI04, DSS01, DSS03, DSS04, MEA01 maka didapatlah hasil kriteria informasi berupa : 
Efektivitas 18,97\%, Efisiensi 26,05\%, Kerahasian 10,72,Integritas 27,55\%, Kepatuhan $16,72 \%$.

Dari semua responden dan berdasarkan pemetaan 15 sub domain yang diwujudkan dalam 11 pertanyaan sebagai berikut bagian dari tujuan bisnis memiliki nilai integritas (integrity) sebesar $27,55 \%$ dari semua responden, terkait dengan ketentuan informasi melalui penggunaan sumber daya secara optimal memiliki nilai efisiensi $26,05 \%$ dari sebuah responden, terkait dengan informasi yang relevan dan berhubungan pada proses bisnis serta disampikan juga tepat waktu, benar, konsisten dan mudah dalam mengelola data memiliki nilai efektivitas sebesar $18,97 \%$ dari semua responden, dan yang terakhir pengamanan terhadap SISMIOP yang sensitif dari pihak yang tidak berhak belum dapat dijaga dengan baik dengan nilai sebesar $10,72 \%$.

Dan dari hasil analisa diatas maka dapat direkapitulasi jawaban responden untuk memenuhi tujuan yang berhubungan dengan teknologi informasi (IT Related Goals) dari kerangka kerja Cobit 5 hasilnya sesuai kriteria informasi yang diperoleh : Efektivitas 9,42\%, Efisiensi $14,64 \%$, Kerahasian 9,25, Integritas 20,24\%, Ketersediaan 9,15\%, Kepatuhan $13,92 \%$, Keandalan 23,38\%.

Setelah dilakukan pengukuran rekapitulasi maka dilakukan lagi hasil perhitungan tingkat kematangan (Maturity level) dalam hasil perhitungan tingkat kematangan ini akan dibagi dalam tiga kelompok yaitu yang pertama perhitungan maturity level kelompok manajer yang berjumlah 4 responden 1. EDM nilai maturity level 2,97\% tingkat Maturity Repeatable but intuitive 2. APO nilai maturity level 3,15\% tingkat Maturity Defined. 3. BAI nilai maturity level 3,04\% tingkat Maturity Defined 4. DSS nilai maturity level 3,06\% tingkat Maturity Defined 5. MEA nilai maturity level 3,01\% tingkat Maturity Defined nilai ratarata nilai maturity level yaitu 3,05 tingkat maturity Defined. Hasil analisa untuk tingkat manager adalah level 3 didefinisikan dengan nilai3,05 dimana :

- Dinas DPPKA Kota Pagar Alam menyadari dan mengetahui kebutuhan pengelolaan layanan SISMIOP.

- Telah direncanakan sekumpulan aturan untuk indikator dasar pengelolaan SISMIOP.

- Seluruh proses telah didokumentasikan dan telah dikomunikasikan serta telah dilaksanakan berdasarkan metode pengembangan komputerisasi yang baik.

- Akan tetapi implementasi diserahkan pada setiap individu sehingga penyimpangan yang terjadi terkadang tidak terdeksi.

Perhitungan Maturity Level kelompok staff merupaka tingkat pelaksana di DPPKA Kota Pagar Alam berjumlah 12 responden 1. EDM nilai maturity level 3,06\% tingkat Maturity Defined 2. APO nilai maturity level 3,27\% tingkat Maturity Defined. 3. BAI nilai maturity level 2,86\% tingkat Maturity Repeatable but intuitive 4. DSS nilai maturity level 2,86\% tingkat Maturity Repeatable but intuitive 5. MEA nilai maturity level 2,86\% tingkat Maturity Repeatable but intuitive. Nilai rata-rata maturity level yaitu 2,98 Tingkat maturity Repeatable but intuitive. Hasil analisa untuk tingkat staff adalah level 2 berulang / Repeatable but intuitive dengan nilai 2,98 dimana: 
- DPPKA Kota Pagar Alam Menyadari adanya kebutuhan akan pentingnya layanan SISMIOP.

- Perencanaan dan Implementasi berbasis komputer telah menemukan pola terarah, berjalan dengan pola terstandar.

- Pihak pimpinan telah mengetahui ukuran dasar pengelolaan layanan SISMIOP tetapi proses tersebut belum dapat diaplikasikan secara menyeluruh di DPPKA Kota Pagar Alam.

- Tidak tersedianya pelatihan formal dan komunikasi mengenai standar layanan SISMIOP.

Perhitungan Maturity level kelompok operator di DPPKA Kota Pagar Alam berjumlah 6 responden 1. EDM nilai maturity level 2,87\% tingkat Maturity Repeatable but intuitive 2. APO nilai maturity level 3,15\% tingkat Maturity Defined. 3. BAI nilai maturity level 2,98\% tingkat Maturity Repeatable but intuitive 4. DSS nilai maturity level 2,78\% tingkat Maturity Repeatable but intuitive 5. MEA nilai maturity level 2,67\% tingkat Maturity Repeatable but intuitive. Nilai rata-rata maturity level yaitu 2,89 Tingkat maturity Repeatable but intuitive. Hasil analisa untuk tingkat operator adalah level 2 berulang / Repeatable but intuitive dengan nilai 2,89 dimana kelompok operator sudah memiliki pemahaman yang sama dengan kelompok staff dalam memahami pentingnya pelayanan SISMIOP sehingga dapat meningkatkan kinerja dan hubungan kerja sama di lingkungan tempat kerja dapat berjalan dengan baik yaitu :

- Mulai menyadari adanya kebutuhan akan pentingnya pelayanan SISMIOP yang baik kepada masyarakat.
- Perencanaan dan implementasi berbasis komputer telah menemukan pola terarah, berjalan dengan pola terstandar serta memiliki koordinasi kerja yang baik dengan kelompok staff (antara pimpinan dengan bawahan).

\section{KESIMPULAN}

Setelah dilakukan tahapan-tahapan analisa, terhadap proses evaluasi tata kelola SISMIOP di DPPKA Kota Pagar Alam sudah memenuhi harapan pemerintah dan masyarakat, yaitu untuk meningkatkan efektivitas pelayanan administrasi Pajak Bumi dan Bangunan kepada masyarakat dan menjamin akurasi basis data SISMIOP.

\section{RUJUKAN}

Direktorat Jenderal Pajak. 2000. Keputusan Direktorat Jendral Pajak Nomor KEP533/PJ/2000 tentang Petunjuk Pelaksanaan Pendaftaran, Pendataan dan Penilaian Objek dan Subjek Pajak Bumi dan Bangunan Dalam Rangka Pembentukan dan atau Pemeliharaan Basis Data Sistem Manajemen Informasi Objek Pajak (SISMIOP). Jakarta

Sasongko, N. 2009. pengukuran kinerja teknologi informasi menggunakan framework cobit versi 4.1, ping test dan caat pada pt.bank $\mathrm{x}$ tbx. Bandung bandung. Seminar Nasional Aplikasi teknologi Informasi.Bandung.

ISACA. 2012. Cobit, Diakses 15 Oktober 2016, dari www.isaca.org/cobit 
